\title{
Rigorous Distillation Dynamics Simulations Using a Computer Algebra
}

\author{
ZAKIA NASRI, HOUSAM BINOUS \\ National Institute of Applied Sciences and Technology, BP 676 Centre Urbain Nord, 1080 Tunis, Tunisia
}

Received 4 June 2009; accepted 26 August 2009

\begin{abstract}
In the present paper, Mathematica ${ }^{\circledR}$, the famous computer algebra, is used to perform steadystate and dynamic simulations of a multi-component distillation column. In order to describe the vapor-liquid equilibrium (VLE) relationships and to compute the vapor- and liquid-phase enthalpies, the SoaveRedlich-Kwong equation of state (SRK EOS) is chosen. Rigorous modeling is performed where both mass and energy balance equations are solved. The Francis weir formula is selected to model column hydraulics. All steadystate results of the column simulations are found to agree very well with those obtained using HYSYS. Finally, some insight into column control is given through the application of both the slope and sensitivity criteria. The computer code, developed at the National Institute of Applied Sciences and Technology (INSAT) in Tunis by the authors, has served to teach several aspects of chemical engineering to senior undergraduate students at INSAT. Indeed, students gain from such code a good understanding of energy and mass balances, column dynamic and control, equations of state and VLE as well as some applied mathematics such as nonlinear algebraic equations, differential-algebraic systems of equations, and how they can be solved using computer algebra such as Mathematica ${ }^{\circledR}$. In addition, they learn about major process simulators such as HYSYS. ( 2009 Wiley Periodicals, Inc. Comput Appl Eng Educ; Published online in Wiley InterScience (www.interscience.wiley.com); DOI 10.1002/ cae. 20385
\end{abstract}

Keywords: distillation; Mathematica ${ }^{\circledR}$; applied thermodynamics; SRK EOS; simulation dynamic and control

\section{INTRODUCTION}

Effluents from chemical reactors need to be separated in order to achieve product purity commercial specifications. Several unit operations are available for this purpose such as adsorption, absorption, and stripping, liquid-liquid extraction, leaching, and last but not least distillation. More than 40,000 distillation units operate in the United States of America alone. This makes the study of such ubiquitous separation method very important in any good standing chemical engineering undergraduate curriculum. Usually, such teaching is based on presenting the McCabe and Thiele method for binary mixtures and some short-cut methods for multi-component mixtures. Rigorous simulations are usually performed using commercial process simulators such as ASPEN PLUS and HYSYS by Aspen Technology, Inc. (http://www.aspentech.com/). Thus students often fail to see the details behind such calculations and the level of complexity of the problems at hand (several hundreds of differential-algebraic equations (DAEs) sometimes of index superior to one). In the present

Correspondence to H. Binous (binoushousam@yahoo.com). (C) 2009 Wiley Periodicals Inc. study, the authors humbly attempt to unveil some of the secrets about such rigorous multi-component distillation simulations using a computer algebra that is widely available in universities around the world and a simple quaternary example. In addition to steady-state simulations, the dynamic behavior of a distillation column was studied in the present work. Indeed, in order to model column start-up and shut-down operations, one has to perform dynamic simulations. Also, a column can be subject to disturbances, in the feed composition or feed flow rate, for example, a situation that requires the good grasp of basic ideas about column dynamic and control. Process dynamic and control is usually taught in a separate course. Distillation columns are generally a good example of a process unit to be selected in order to particle such techniques.

In the first section, we present the fluid package used, which is the Soave-Redlich-Kwong (SRK) Equation of State (EOS). The system of DAEs that must be solved in order to obtain information about the column's temperature, composition, etc. is given in The Mass and Energy Balance Equations Section. Then, the Francis weir formula is given. This formula allows one to model the column hydraulics. We perform steady-state simulations and compare our results with those obtained with HYSYS 3.2, a major process simulator by Aspen Technology, 
Inc. (http://www.aspentech.com/), in Steady-State Simulation Results Section. Then, the authors present the results of the dynamic simulations of the distillation column by making step changes in reflux ratio and rebolier heat duty. In the last section, we apply the slope and sensitivity criteria in order to gain some insights into how one should control the column. Finally, in the conclusion, the authors share their experience teaching chemical engineering problems with the help of computer software such as Mathematica ${ }^{\mathbb{R}}$ and HYSYS

\section{THE SOAVE-REDLICH-KWONG EQUATION OF STATE}

For a pure component, the SRK EOS [1-5] is given by

$$
P=\frac{R T}{(V-b)}-\frac{a}{V(V+b)}
$$

where

$$
\begin{gathered}
b=0.08664 \frac{R T_{\mathrm{c}}}{P_{\mathrm{c}}} \\
a=0.42748 \frac{\left(R T_{\mathrm{c}}\right)^{2}}{P_{\mathrm{c}}}\left(1+m\left(1-\sqrt{T_{\mathrm{r}}}\right)\right)^{2} \\
T_{\mathrm{r}}=\frac{T}{T_{\mathrm{c}}}
\end{gathered}
$$

and

$$
m=0.480+1.574 \omega-0.176 \omega^{2}
$$

The SRK EOS is part of a family of equations called cubic because the compressibility factor, $Z=P V / R T$, is a solution of a cubic equation. This equation, written for a multi-component mixture where we have used the mixing and combining rules, is as follows:

$$
Z^{3}-Z^{2}+Z\left(A-B-B^{2}\right)-A B=0
$$

where

$$
\begin{gathered}
A=\sum_{i=1}^{C} \sum_{j=1}^{C} y_{i} y_{j} A_{i j} \quad \text { or } \quad \sum_{i=1}^{C} \sum_{j=1}^{C} x_{i} x_{j} A_{i j} \\
A_{i j}=\left(A_{i} A_{j}\right)^{0.5}\left(1-k_{i j}\right) \\
B=\sum_{i=1}^{C} y_{i} B_{i} \quad \text { or } \quad \sum_{i=1}^{C} x_{i} B_{i} \\
A_{i}=0.42747 a_{i} \frac{P_{\mathrm{r}_{i}}}{T_{\mathrm{r}_{i}}^{2}} \quad \text { and } \quad B_{i}=0.08664 \frac{P_{\mathrm{r}_{i}}}{T_{\mathrm{r}_{i}}}
\end{gathered}
$$

For each component, we define the reduced pressure and temperature by $P_{\mathrm{r}_{i}}=P / P_{c_{i}}$ and $T_{\mathrm{r}_{i}}=T / T_{c_{i}}$, and $a_{i}$ is given by the same equation as Equation (3) given for the pure component case. The binary interaction parameter, $k_{i j}$, is assumed to be equal to 0 if not available or taken from HYSYS. The equilibrium constants are obtained using the $\phi-\phi$ method as follows:

$$
K_{i}=\frac{\phi_{\mathrm{l}_{i}}}{\phi_{\mathrm{v}_{i}}} \quad \text { for } \quad i=1 \text { to } N_{c}
$$

where

$$
\begin{aligned}
\phi_{\mathrm{v}_{i}}= & \exp \left(\left(Z_{\mathrm{v}}-1\right) \frac{B_{i}}{B}-\ln \left(Z_{\mathrm{v}}-B\right)-\frac{A}{B}\left(\frac{2 A_{i}^{0.5}}{A^{0.5}}-\frac{B_{i}}{B}\right)\right. \\
& \left.\ln \left(\frac{Z_{\mathrm{v}}+B}{Z_{\mathrm{v}}}\right)\right)
\end{aligned}
$$

A similar expression is obtained for the liquid-phase fugacity coefficient, $\phi_{1_{i}}$, by replacing the gas-phase compressibility factor, $Z_{\mathrm{v}}$ with its liquid-phase counterpart, $Z_{1}$. These two compressibility factors are the largest and smallest roots of Equation (6), respectively.

The liquid and vapor mole fractions are related by

$$
y_{i}=K_{i} x_{i} \quad \text { with } \quad i=1 \text { to } N_{c}
$$

where $K_{i}$ is the equilibrium constant.

One also needs the following expression for the departure function from ideality for the enthalpy in order to compute feed enthalpy as well as the liquid and vapor enthalpy in all stages [4]:

$$
\begin{gathered}
H^{\mathrm{D}}= \\
{\left[T T(Z-1)+\frac{1}{B(R T / P)} \ln \left(\frac{Z+B}{\mathrm{~d} T}\right)\right.} \\
\left.\left[A \frac{\mathrm{d}}{P}\right)-A \frac{(R T)^{2}}{P}\right]
\end{gathered}
$$

where the compressibility factor is equal to: (i) $Z_{\mathrm{v}}$ for vapor enthalpy, (ii) $Z_{1}$ for liquid enthalpy, and (iii) $Z_{\mathrm{f}}$ for the feed, which is considered in the present study as saturated liquid.

It is the authors' experience that all computations relative to the SRK EOS can be performed using Mathematica ${ }^{\circledR}[6]$.

\section{THE MASS AND ENERGY BALANCE EQUATIONS}

In the present section, we give the governing equations that allow the steady-state and dynamic simulations to be performed. They are composed of the total and partial mass balances and the energy balance around the feed stage, the partial reboiler, the total condenser, and any tray other than the feed tray. These balance equations, written separately for all the column sections mentioned above (see Fig. 1), are the following:

(1) Feed tray $(k=f)$ :

$$
\begin{aligned}
& \frac{\mathrm{d} M_{f}}{\mathrm{~d} t}=F+L_{f-1}+V_{f+1}-L_{f}-V_{f} \\
& \frac{\mathrm{d}\left(M_{f} x_{f, i}\right)}{\mathrm{d} t}=F z_{f, i}+L_{f-1} x_{f-1, i}+V_{f+1} y_{f+1, i} \\
& -L_{f} x_{f, i}-V_{f} y_{f, i} \text { for } i=1,2, \ldots, N_{\mathrm{c}} \\
& \frac{\mathrm{d}\left(M_{f} h_{f}\right)}{\mathrm{d} t}=F h_{F}+L_{f-1} h_{f-1}+V_{f+1} H_{f+1}-L_{f} h_{f}-V_{f} H_{f}
\end{aligned}
$$

(2) $k$ th tray $(k \neq f$ and $1<k<N)$ :

$$
\begin{aligned}
& \frac{\mathrm{d} M_{k}}{\mathrm{~d} t}=L_{k-1}+V_{k+1}-L_{k}-V_{k} \\
\frac{\mathrm{d}\left(M_{k} x_{k, i}\right)}{\mathrm{d} t}= & L_{k-1} x_{k-1, i}+V_{k+1} y_{k+1, i} \\
& -L_{k} x_{k, i}-V_{k} y_{k, i} \text { for } i=1,2, \ldots, N_{\mathrm{c}}
\end{aligned}
$$




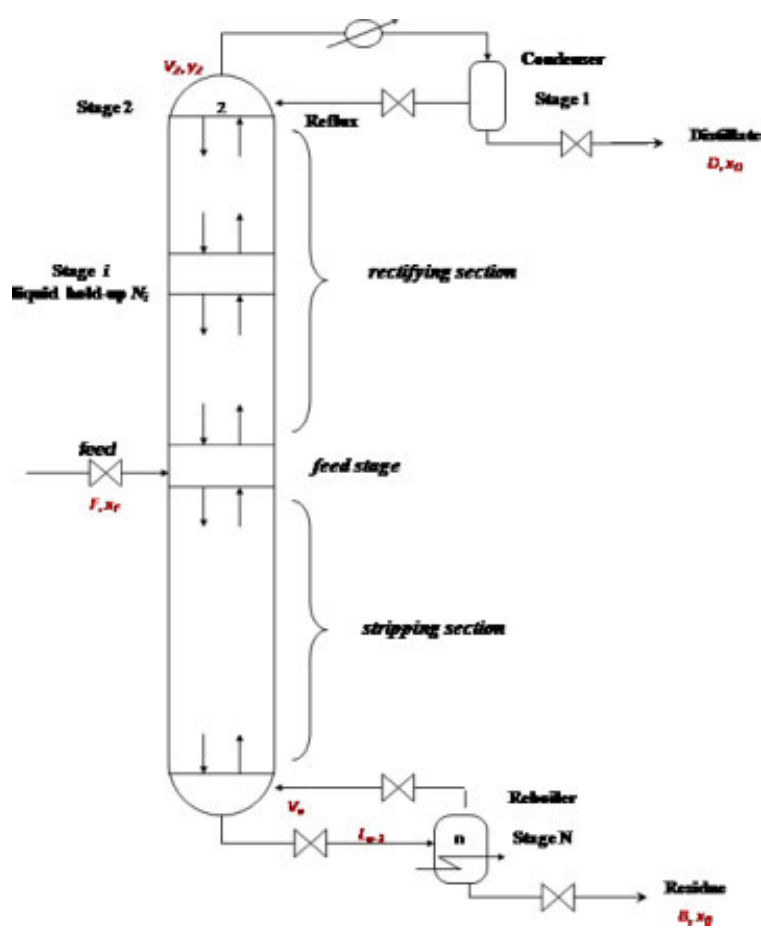

Figure 1 Schematic of a distillation column.

$$
\frac{\mathrm{d}\left(M_{k} h_{k}\right)}{\mathrm{d} t}=L_{k-1} h_{k-1}+V_{k+1} H_{k+1}-L_{k} h_{k}-V_{k} H_{k}
$$

(3) Reflux drum $(k=1)$ :

$$
\begin{gathered}
\frac{\mathrm{d} M_{1}}{\mathrm{~d} t}=V_{2}-\left(L_{1}+D\right) \\
\frac{\mathrm{d}\left(M_{1} x_{1, i}\right)}{\mathrm{d} t}=V_{2} y_{2, i}-\left(L_{1}+D\right) x_{\mathrm{D}, i} \quad \text { for } \quad i=1,2, \ldots, N_{\mathrm{c}}
\end{gathered}
$$

$$
\frac{\mathrm{d}\left(M_{1} h_{1}\right)}{\mathrm{d} t}=V_{2} H_{2}-\left(L_{1}+D\right) h_{1}-\dot{Q}_{\mathrm{C}}
$$

(4) Reboiler $(k=N)$ :

$$
\begin{gathered}
\frac{\mathrm{d} M_{N}}{\mathrm{~d} t}=L_{N-1}-L_{N}-V_{N} \\
\frac{\mathrm{d}\left(M_{N} x_{N, i}\right)}{\mathrm{d} t}=L_{N-1} x_{N-1, i}-L_{N} x_{N, i}-V_{N} y_{N, i} \quad \text { for } i=1,2, \ldots, N_{\mathrm{c}}
\end{gathered}
$$

$$
\frac{\mathrm{d}\left(M_{N} h_{N}\right)}{\mathrm{d} t}=L_{N-1} h_{N-1}-L_{N} h_{N}-V_{N} H_{N}+\dot{Q}_{\mathrm{B}}
$$

In the equations above, we have made the usual assumption where vapor molar hold-up is neglected, which may give erroneous results for very high column pressures [7]. In addition, for the energy equation, we used the full differential equation (i.e., we did not set the LHS of the energy balance equations equal to 0$)$ rather than an algebraic equation, which neglect the time derivative. Indeed, this second approach may cause certain problems [8] despite the fact that the dynamics of the energy equations are usually very fast

\section{THE FRANCIS WEIR FORMULA}

The momentum balance for each tray is neglected. The Francis weir formula is assumed and provides additional equations. Indeed, for each stage $k$, we have a relationship between the tray liquid hold-up, $M_{k}$, and the liquid molar flow rate leaving the $k$ th stage, $L_{k}$ :

$$
M_{k}=\frac{\rho_{k, 1}}{\sum_{i=1}^{N_{\mathrm{c}}} x_{k, i} M_{w, i}} A_{\mathrm{a}}\left[h_{\mathrm{w}}+1.41\left(\frac{L_{k} \sum_{i=1}^{N_{\mathrm{c}}} x_{k, i} M_{w, i}}{\rho_{k, 1} l \sqrt{g}}\right)\right]
$$

where

$$
\rho_{k, 1}=\frac{P \sum_{i=1}^{N_{\mathrm{c}}} x_{k, i} M_{w, i}}{Z_{k, 1} R T}
$$

For the total condenser and partial reboiler, we make the following assumption concerning their volume, $V_{0}$ :

$$
V_{0}=0.5 \mathrm{~m}^{3}=M_{k} \frac{Z_{k, 1} R T}{P} \quad \text { for } k=1 \text { or } N
$$

The Francis formula is only used in the dynamic simulation where the liquid molar hold-up in all trays must be determined.

\section{STEADY-STATE SIMULATION RESULTS}

Consider a multi-component mixture to be fed to a distillation column containing $N=27$ theoretical stages, a total condenser, and a partial reboiler and operating at a pressure of 16.212 bar. We assume that (i) the pressure is constant on all trays. A rigorous simulation, where variable pressure in the column is considered, using Fortran 77, is available in the book by Luyben [9]. Another treatment where variable pressure is considered is given by Choe and Luyben [7], (ii) the vapor and liquid leaving each tray are in equilibrium (i.e., tray efficiency is $100 \%$ ), and (iii) the column is adiabatic. The column feed, a saturated liquid, is composed of $2.5 \%$ ethane, $35 \%$ propane, $60 \% n$-butane, and $2.5 \% n$-pentane at $T=347.8 \mathrm{~K}$. Feed flow rate is set equal to $300 \mathrm{kmol} / \mathrm{h}$. The feed is entered at the 13th stage. The reflux ratio and reboiler heat duty are chosen equal to 3.073 and $1.932 \times 10^{6} \mathrm{~kJ} / \mathrm{h}$, respectively. Composition profiles in the column are given in Figure 2a,b. We find perfect agreement between our results and the data provided by the HYSYS simulation. The temperature profile, equilibrium constants, liquid and vapor flow rates, and liquid and vapor molecular weights, obtained thanks to the computer algebra Mathematica $^{\mathbb{R}}$, are plotted in Figures 3-6. All these results are in agreement with what one gets with HYSYS. It is found that vapor and liquid molar flow rates are not constant in both the stripping and rectifying sections of the column. This represents a justification for making rigorous calculation taking both mass and energy balances into account and not assuming the usual constant molar overflow (CMO) hypothesis. Liquid density in the column is given in Figure 7a,b. The reader should note that he must specify to HYSYS "Use EOS Density" in order to get results in agreement with the present study using Mathematica ${ }^{\mathbb{R}}$. It is found that the distillate bubble-point temperature is equal to $301.21 \mathrm{~K}$, which allows the use of cold water utility in the condenser and justifies a posteriori the use of a column pressure 


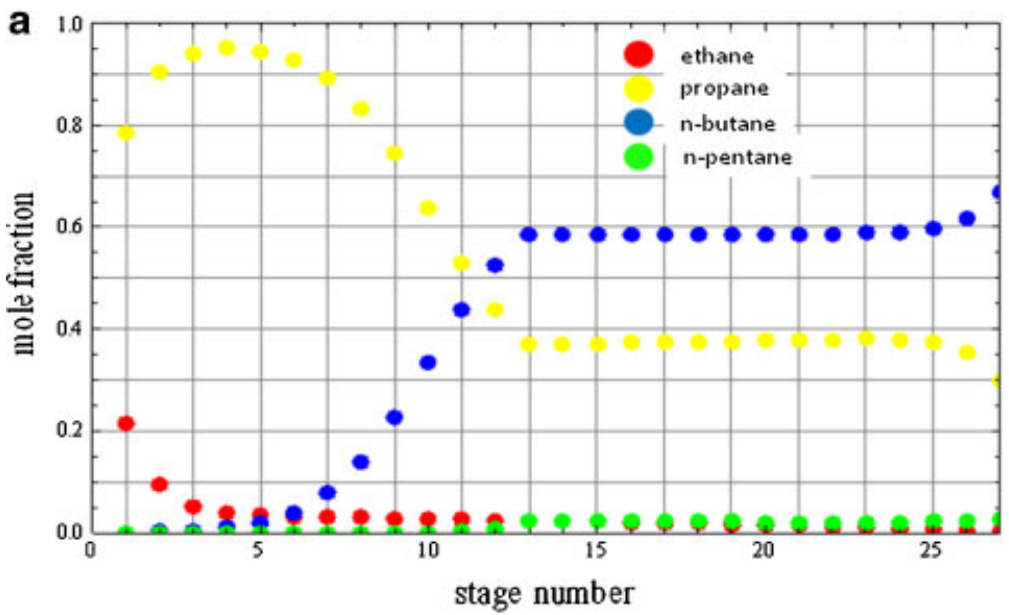

b

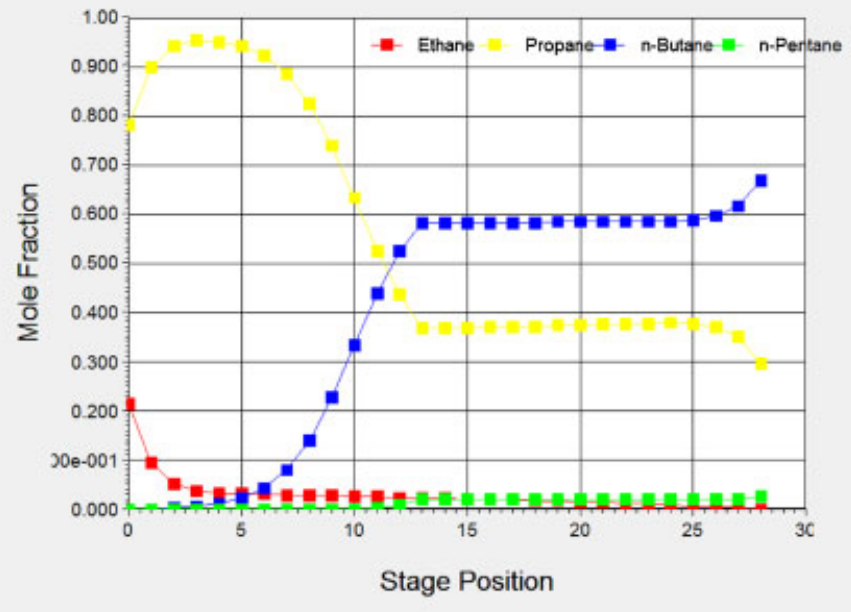

Figure 2 Mole fractions of ethane, propane, $n$-butane, and $n$-pentane versus stage number: (a) present work and (b) HYSYS simulation. [Color figure can be viewed in the online issue, which is available at www.interscience.wiley.com.]

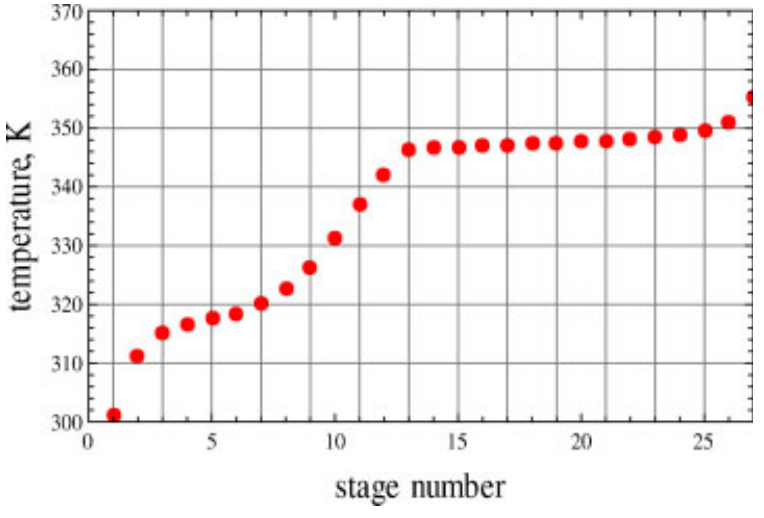

Figure 3 Temperature profile in the column. [Color figure can be viewed in the online issue, which is available at www.interscience.wiley.com.]

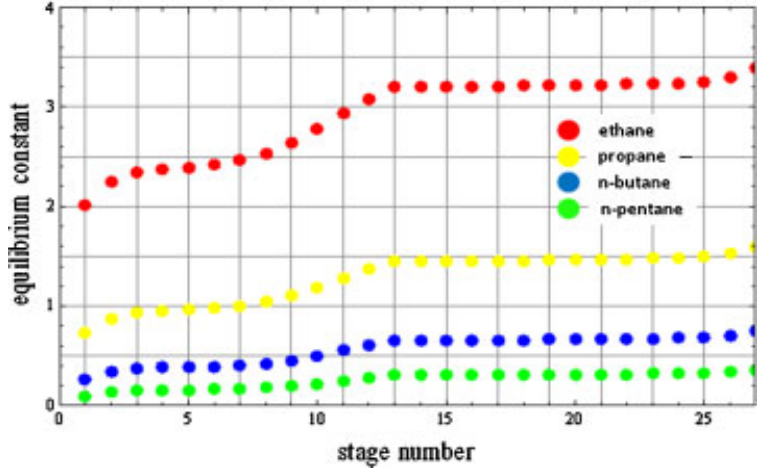

Figure 4 Equilibrium constants for ethane, propane, $n$-butane, and $n$-pentane. [Color figure can be viewed in the online issue, which is available at www.interscience.wiley.com.] 


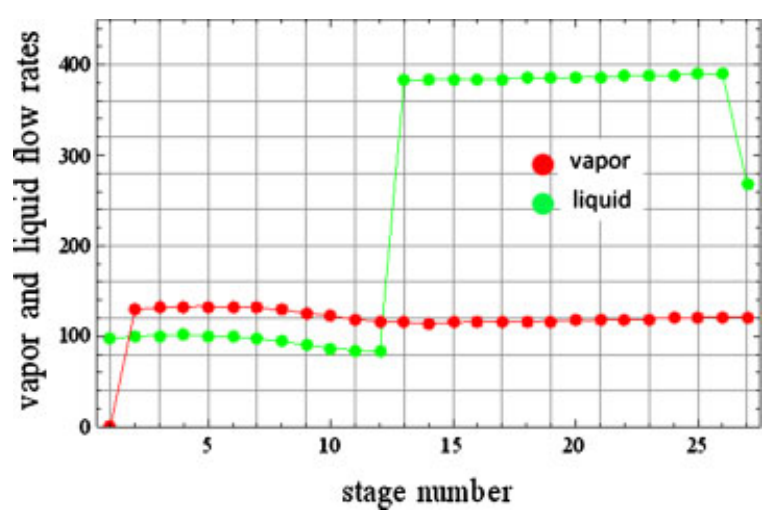

Figure 5 Vapor and liquid flow rates in $\mathrm{kmol} / \mathrm{h}$. [Color figure can be viewed in the online issue, which is available at www. interscience.wiley.com.]

of 16.212 bar. The condenser heat duty is determined to be equal to $1.77363 \times 10^{6} \mathrm{~kJ} / \mathrm{h}$. The bottom and distillate rates are equal to 268.17 and $31.83 \mathrm{kmol} / \mathrm{h}$, respectively. The Mathematica ${ }^{\mathbb{R}}$ built-in command used to solve the system of nonlinear algebraic equations is FindRoot. Here, we have solved a system of 297 nonlinear algebraic equations in $1.81 \mathrm{~s}$ using an Intel ${ }^{\mathbb{R}} \mathrm{Core}^{\mathrm{TM}}$ 2 DUO CPU T 8300 at $2.4 \mathrm{GHz}$ with $3 \mathrm{~Gb}$ of memory.

\section{DYNAMIC SIMULATION RESULTS}

The dynamic simulation requires solving a system of 325 DAEs using the built-in Mathematica ${ }^{\mathbb{R}}$ command, NDSolve. When we apply a step change in the reflux ratio or reboiler heat duty, it is important that the initial conditions be a solution of the steadystate simulation unless NDSolve may adjust the initial conditions, so that these latter give zero residual for the system of DAEs, or worse NDSolve may fail in finding a solution to the system of DAEs. We performed in this study both a $5 \%$ step in the reflux ratio at $t=10 \mathrm{~h}$ (see Fig. 8) and a 5\% step in the reboiler heat duty at $t=10 \mathrm{~h}$. The dynamic simulation results are obtained in less than $12.37 \mathrm{~s}$ using an Intel $^{\circledR}$ Core $^{\mathrm{TM}} 2$ DUO CPU T8300 at $2.4 \mathrm{GHz}$ with $3 \mathrm{~Gb}$ of memory.

Figures 9 and 10 show the molar fractions of all components versus time for a step change in the reflux ratio for the distillate

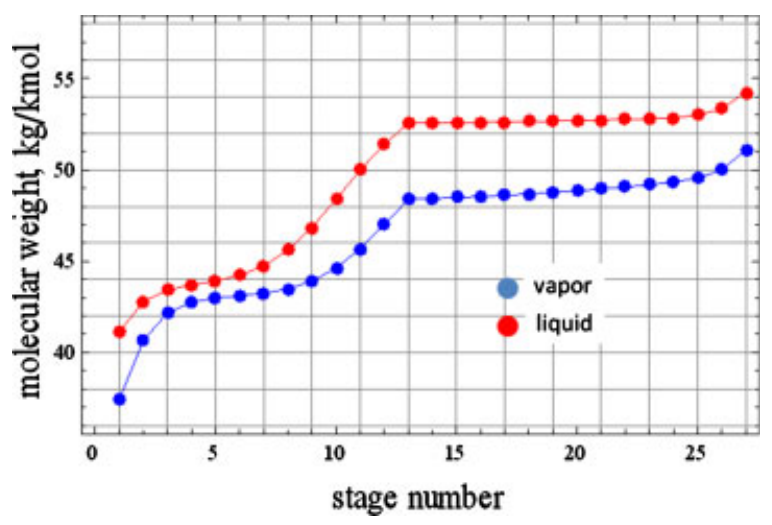

Figure 6 Vapor and liquid molecular weight versus stage number. [Color figure can be viewed in the online issue, which is available at www.interscience.wiley.com.]
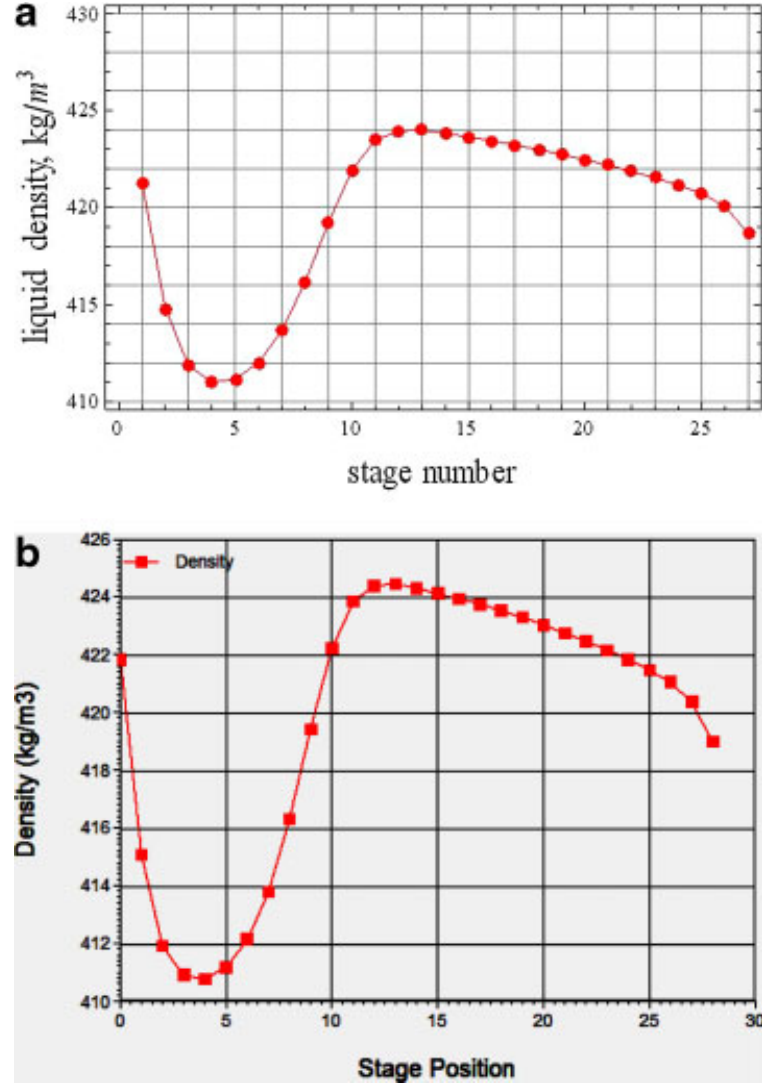

Figure 7 Liquid density versus stage number: (a) present work and (b) HYSYS simulation.

and bottom, respectively. Figures 11 and 12 are a representation of the molar fractions of all components versus time for a step change in the reboiler heat duty for the distillate and bottom, respectively. Finally, one can easily study the response of the dynamic system to a perturbation in the feed flow rate. A 5\% step in the feed flow rate gives the results shown in Figures 13 and 14.

In all the cases studied above, we observe that the new steady state, corresponding to the new values set for the reflux ratio and heat duty or feed low rate, is reached after a transient period of approximately $1 \mathrm{~h}$, which starts at $t=10 \mathrm{~h}$. It is easy to take advantage the fact that the computations are made using

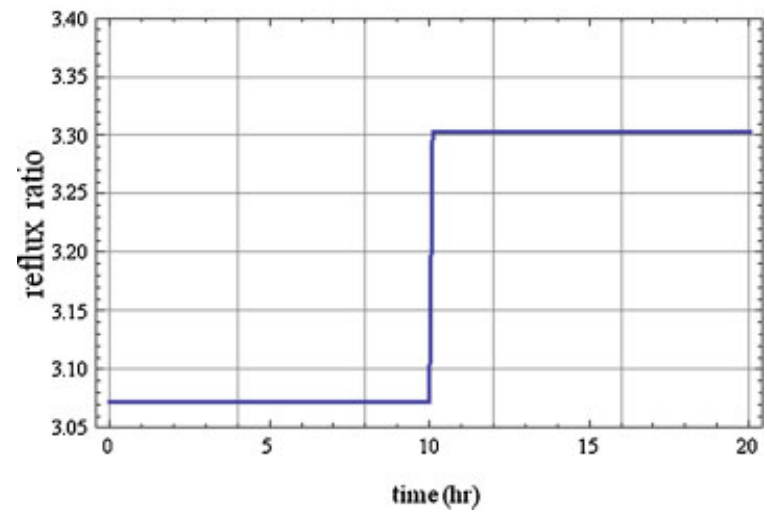

Figure 8 Reflux ratio versus time (a 5\% step). 

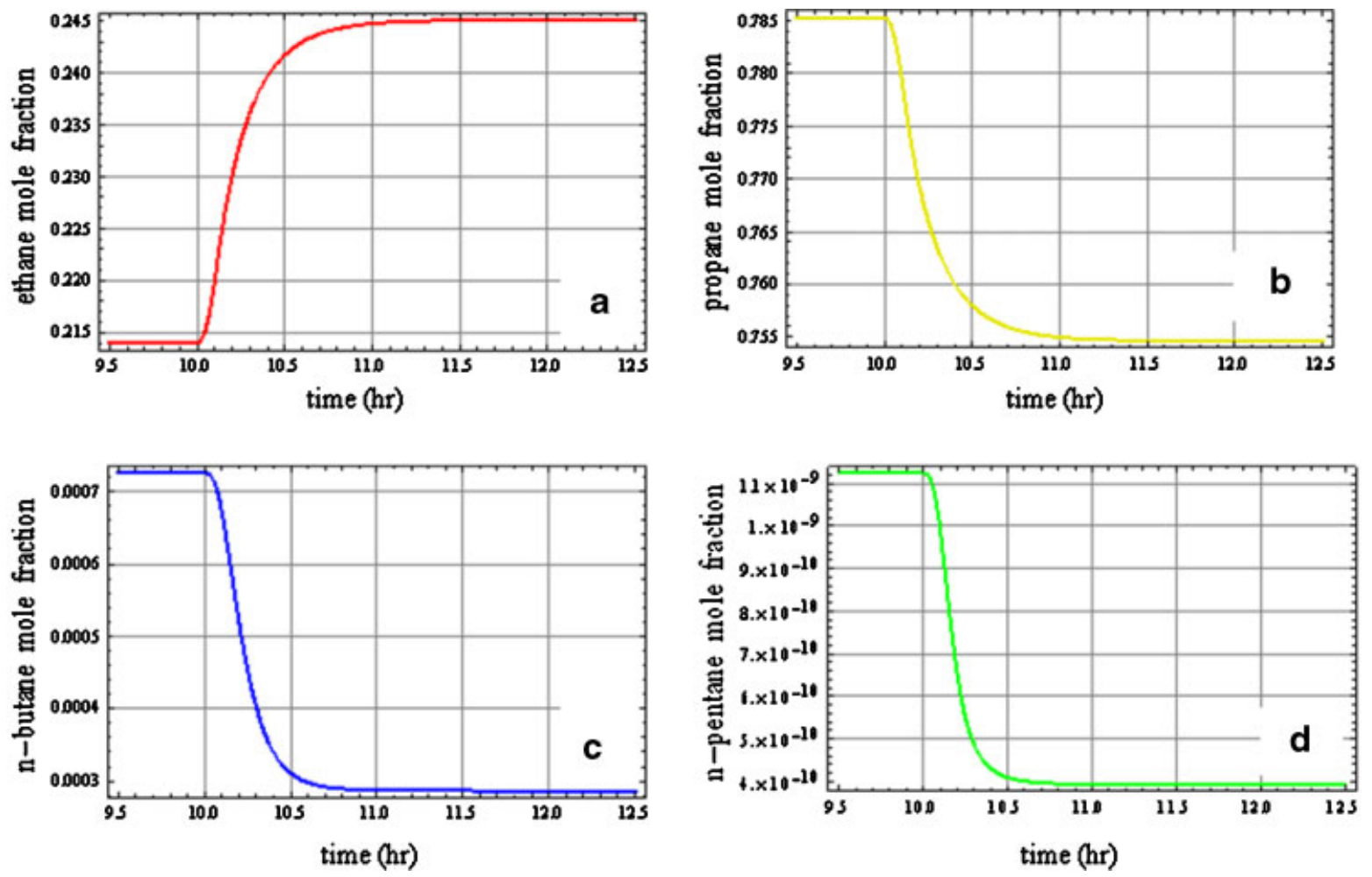

Figure 9 Mole fractions versus time in the distillate for a step in the reflux ratio: (a) ethane, (b) propane, (c) $n$-butane, and (d) $n$-pentane.
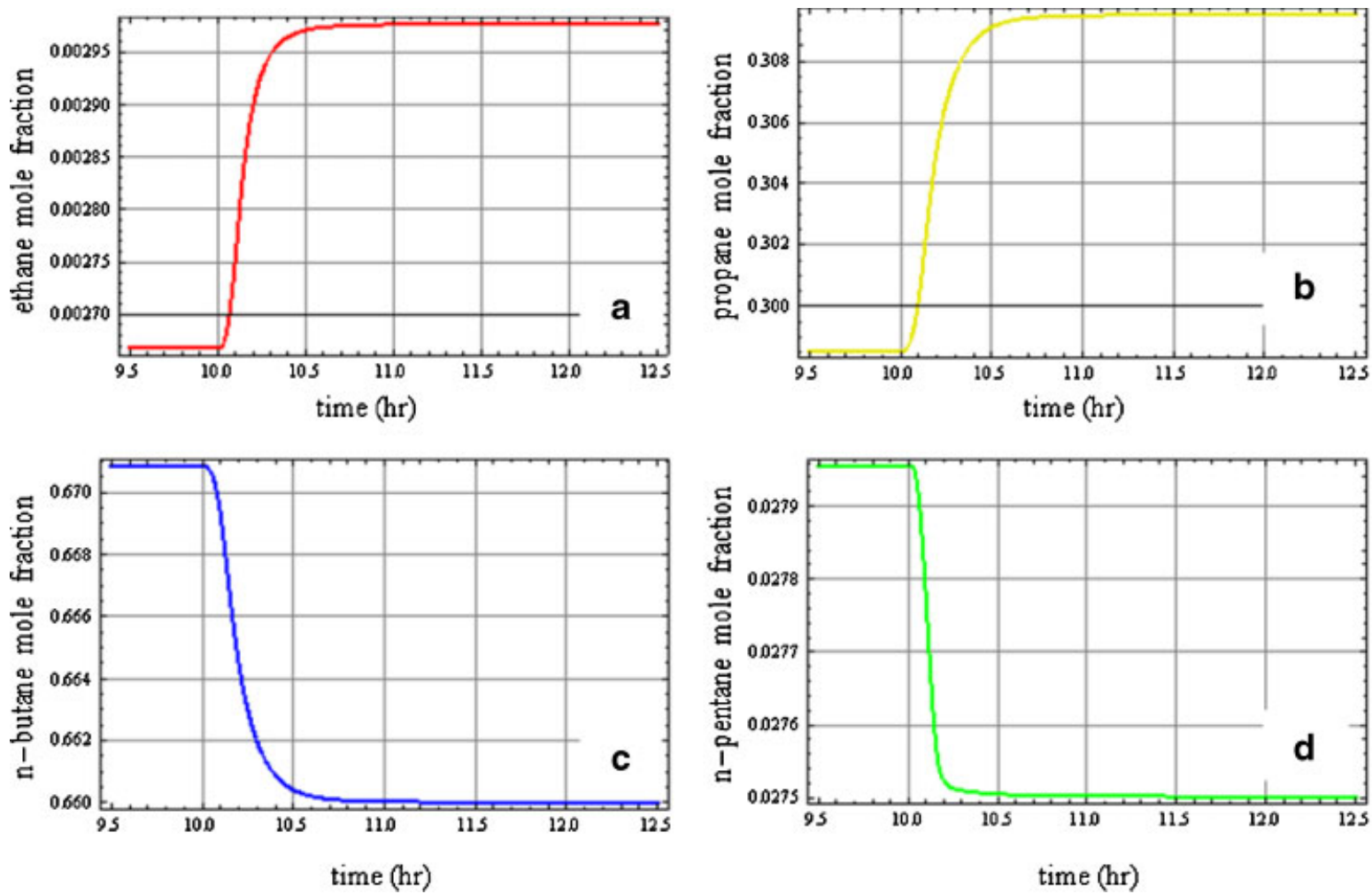

Figure 10 Mole fractions versus time in the bottom for a step in the reflux ratio: (a) ethane, (b) propane, (c) $n$-butane, and (d) $n$-pentane. 

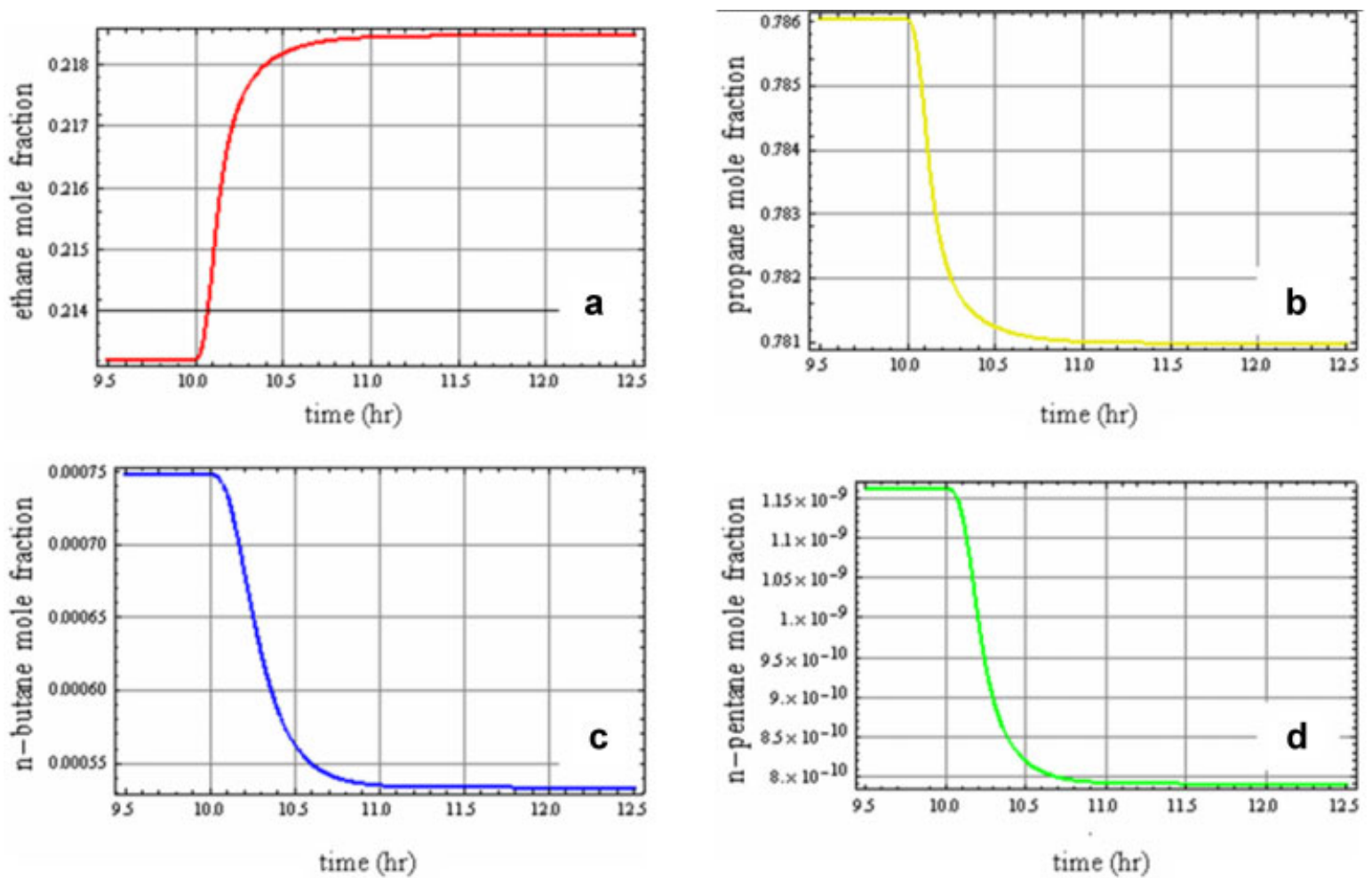

Figure 11 Mole fractions versus time in the distillate for a step in the reboiler heat duty: : (a) ethane, (b) propane, (c) $n$-butane, and (d) $n$-pentane.
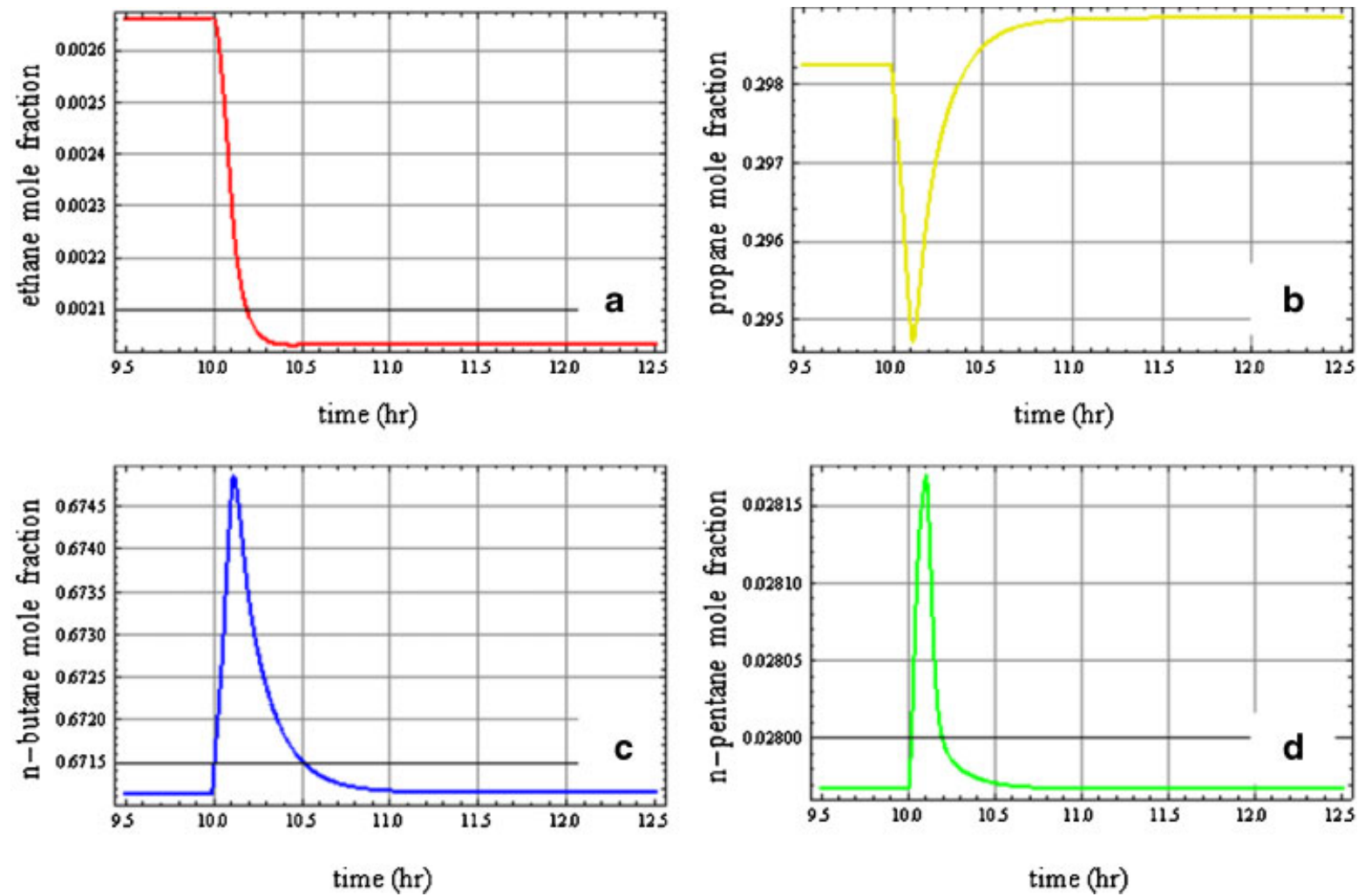

Figure 12 Mole fractions versus time in the bottom for a step in the reboiler heat duty: : (a) ethane, (b) propane, (c) $n$-butane, and (d) $n$-pentane. 

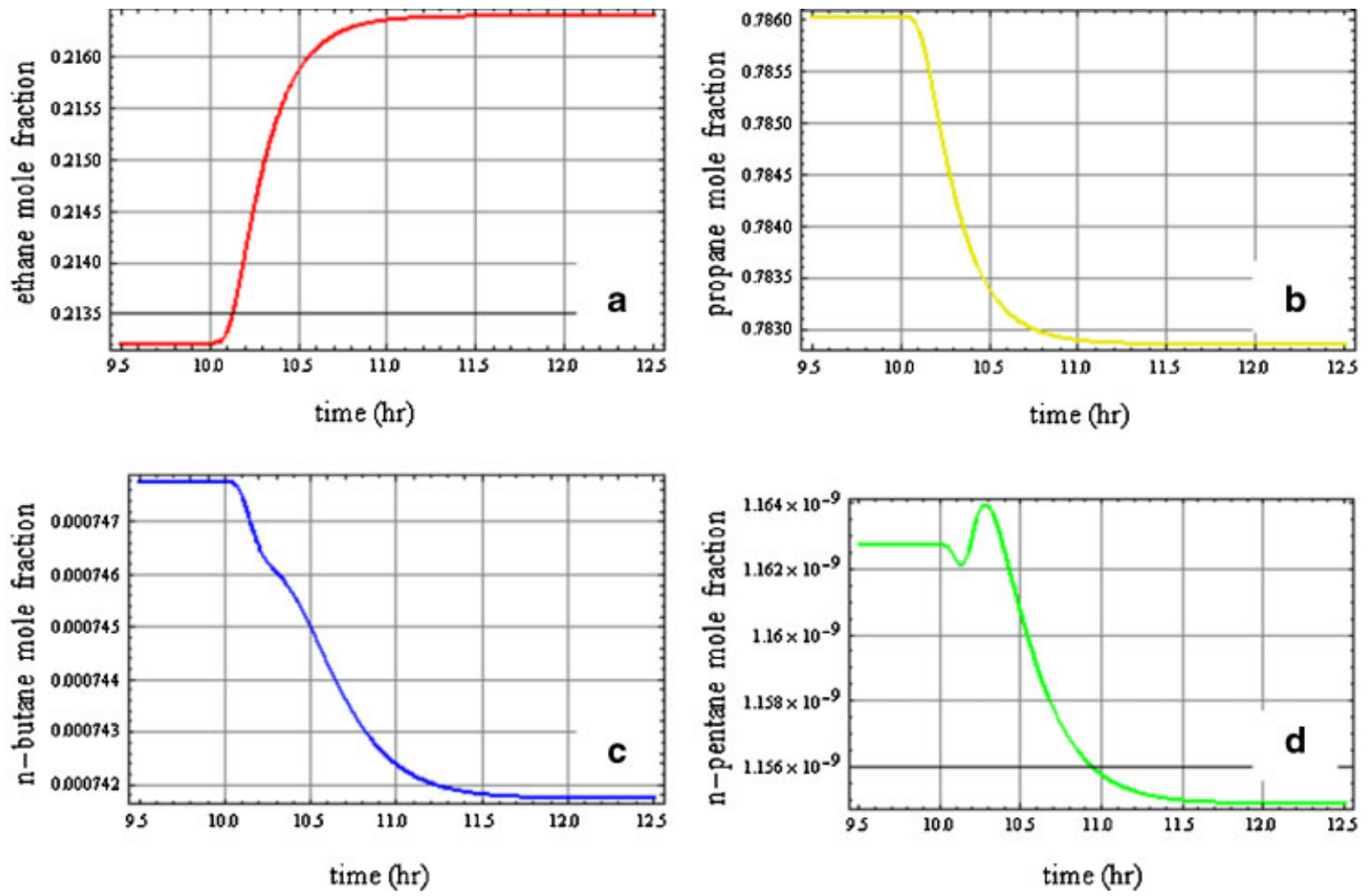

Figure 13 Mole fractions versus time in the distillate for a step in the feed flow rate: : (a) ethane, (b) propane, (c) $n$-butane, and (d) $n$-pentane.
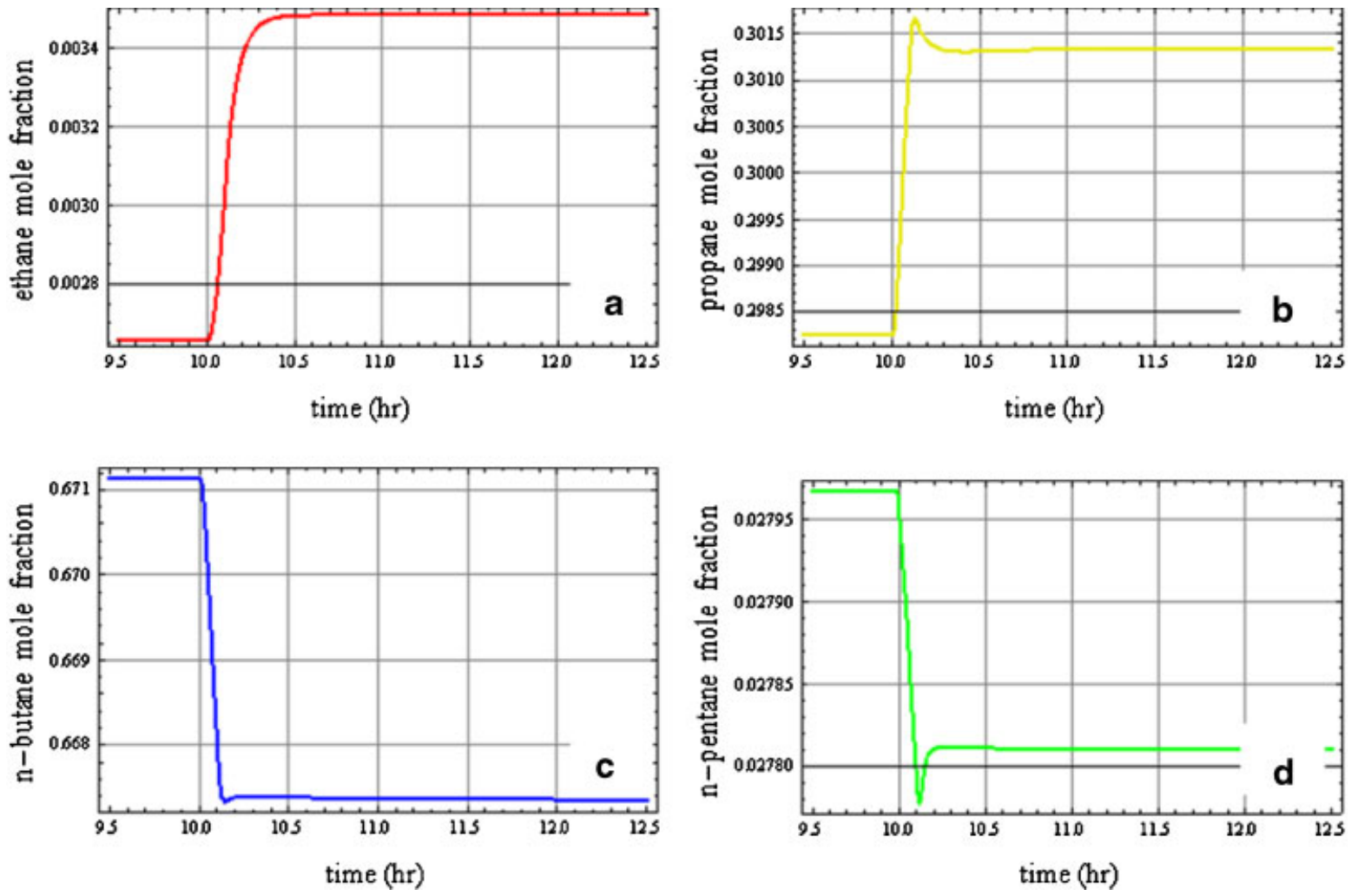

Figure 14 Mole fractions versus time in the bottom for a step in the feed flow rate: : (a) ethane, (b) propane, (c) $n$-butane, and (d) $n$-pentane. 


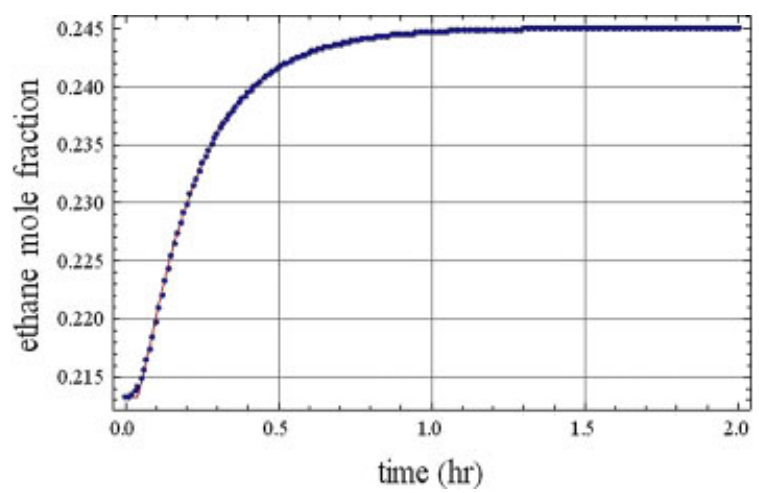

Figure 15 Ethane mole fraction in the distillate for a 5\% step in the reflux ratio at $t=0$.

Mathematica ${ }^{\circledR}$ in order to find the transfer function. These functions were obtained using two built-in functions of Mathematica ${ }^{\circledR}$ : FindFit and LaplaceTransform. They are given, for instance, for the ethane mole fraction in the distillate and bottom $\left(G_{\mathrm{D}}\right.$ and $G_{\mathrm{B}}$, respectively), for a $5 \%$ step in the reflux ratio at $t=0 \mathrm{~h}$, by

$$
G_{\mathrm{D}}=\frac{\mathrm{e}^{-0.05 s}\left(1.0279+(6.8874+1.3879 s) \mathrm{e}^{0.05 s}\right)}{4.9621+s}
$$

and

$$
G_{\mathrm{B}}=\frac{0.0173 \mathrm{e}^{-0.05 s}\left(1.0341+(8.66675+s) \mathrm{e}^{0.05 s}\right)}{8.6675+s}
$$

Figures 15 and 16 show the dynamic response of the ethane mole fraction in the distillate and bottom using the transfer function, shown in red, given above as well as the data points, shown as blue dots, from the dynamic simulation. One can readily apply such transfer functions in order to control the distillation column using the well-known Wood and Berry [10] method and SIMULINK ${ }^{\circledR}$.

\section{THE SLOPE AND SENSITIVITY CRITERIA}

In order to perform good control of a distillation column, one must select the trays where there are the largest changes in

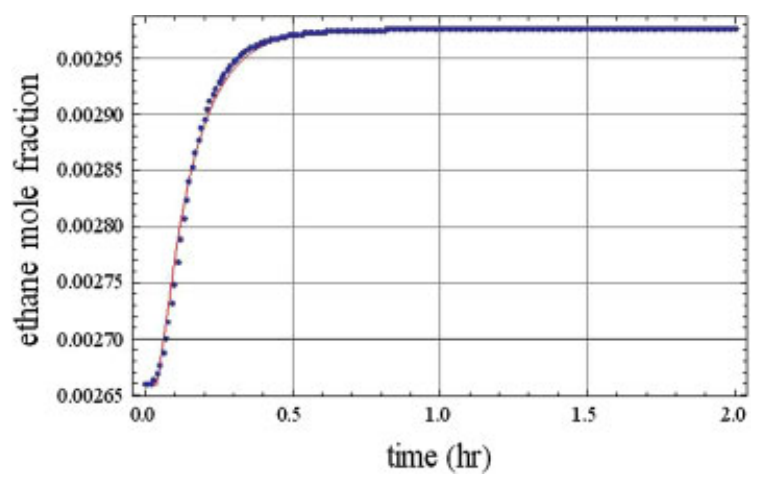

Figure 16 Ethane mole fraction in the bottom for a 5\% step in the reflux ratio at $t=0$.

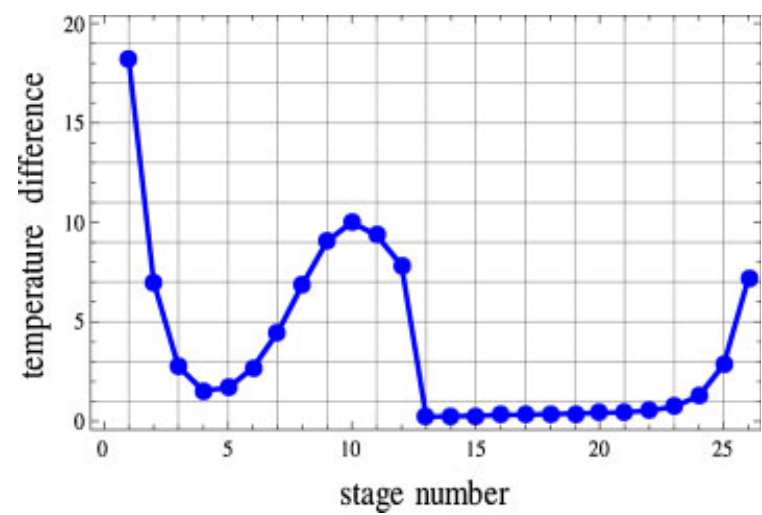

Figure 17 Application of the slope criterion to the distillation column.

temperature from tray to stray. Indeed, large changes in temperature from stage to stage are indicative of a section of the column where mole fractions of important components are changing. Thus, one must maintain temperature at this column position. This method is called the slope criterion [11]. We have computed the slope of the temperature profile given in Figure 3. Result is shown in Figure 17 and clearly indicates that stage 10 and stages near the reboiler and the condenser as candidate locations where temperature should be controlled.

In order to apply the sensitivity criterion [11], we apply a 7.5\% step change in the reflux ratio, which is one of the two manipulated variables (i.e., the reflux ratio and the reboiler heat duty). We look for the locations where there are the largest changes in temperature. Results, shown in Figure 18, are in agreement with those found using the slope criterion. They clearly indicate that stage 10 and the condenser as candidate locations for temperature control.

\section{CONCLUSION}

We have shown how one can successfully apply computer algebra such as Mathematica ${ }^{\circledR}$ to perform static and dynamic simulations. Relatively large systems of nonlinear algebraic equations and DAEs can be solved very rapidly thanks to the builtin commands of Mathematica ${ }^{\circledR}$, FindRoot, and NDSolve,

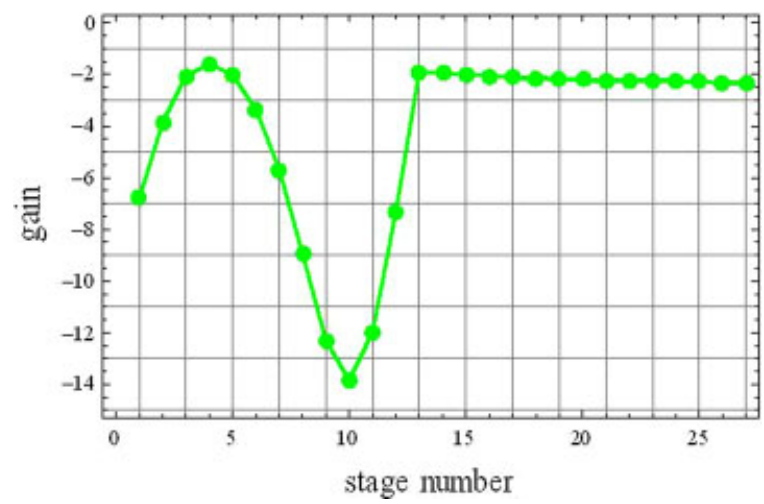

Figure 18 Application of the sensitivity criterion to the distillation column. 
respectively. The steady-state and dynamic results were compared to those obtained using HYSYS. Then, they were used to perform slope and sensitivity analyses in order to gain insight regarding column control. All computer codes are available, in the form of a Mathematica ${ }^{\circledR}$ notebook, upon request from the corresponding author. These codes are among a series of computer programs, developed by Dr. Housam Binous at the National Institute of Applied Sciences and Technology (INSAT) in Tunis, in order to help his senior and junior students gain insight into unit operation problems such as distillation, absorption, leaching, liquid-liquid extraction, etc. In addition, the nontrivial nature of the mathematical problem at hand (i.e., large complex systems of DAEs and nonlinear algebraic equations) makes these codes useful to the applied mathematics course taught by the corresponding author at INSAT. Finally, a new computer laboratory, where Mathematica ${ }^{\mathbb{R}}$ and MATLAB ${ }^{\mathbb{R}}$ are taught simultaneously to senior students, has also profited from these recent developments and new way of teaching science.

\section{NOMENCLATURE}

$A_{\mathrm{a}} \quad$ active area of the stage $\left(\mathrm{m}^{2}\right)$

$B$ bottom flow rate $(\mathrm{kmol} / \mathrm{h})$

$D$ distillate flow rate $(\mathrm{kmol} / \mathrm{h})$

$d$ column inside diameter (m)

$F$ feed flow rate $(\mathrm{kmol} / \mathrm{h})$

g $9.81\left(\mathrm{~m}^{2} / \mathrm{s}\right)$

$H \quad$ vapor enthalpy $(\mathrm{kJ} / \mathrm{kmol})$

$h_{\mathrm{w}} \quad$ weir height $(\mathrm{m})$

$h$ liquid enthalpy $(\mathrm{kJ} / \mathrm{kmol})$

$K_{i} \quad$ equilibrium constant

$L \quad$ liquid molar flow rate $(\mathrm{kmol} / \mathrm{h})$

$l \quad$ weir length $(\mathrm{m})$

$M_{k} \quad$ liquid hold-up (kmol)

$M_{\mathrm{w}}$ molecular weight $(\mathrm{kg} / \mathrm{kmol})$

$N \quad$ number of trays in the column

$N_{\mathrm{c}}$ number of components in the mixture

$P \quad$ column pressure (bar)

$P_{\mathrm{c}, i}$ critical pressure (bar)

$P_{\mathrm{r}, i} \quad$ reduced pressure

$\dot{Q}_{\text {B }} \quad$ reboiler heat duty $(\mathrm{kJ} /(\mathrm{kmol} \mathrm{h}))$

$\dot{Q}_{\mathrm{C}} \quad$ condenser heat duty $(\mathrm{kJ} /(\mathrm{kmol} \mathrm{h}))$

$R$ reflux ratio

$t$ time (h)

$T$ temperature (K)

$T_{\mathrm{c}, i} \quad$ critical temperature (K)

$T_{\mathrm{r}, i}$ reduced temperature

$V \quad$ vapor flow rate $(\mathrm{kmol} / \mathrm{h})$

\section{BIOGRAPHIES}

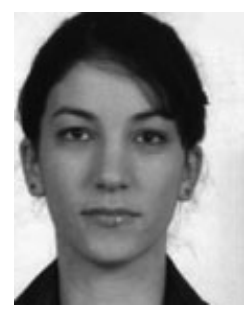

Zakia Nasri is a PhD student at the National Institute of Applied Sciences and Technology in Tunis. She earned a Masters degree and a Diplôme d'ingénieur in Industrial Chemistry from the National Institute of Applied Sciences and Technology in Tunis. Her research interests are in applied thermodynamics and petroleum engineering. liquid composition (mole fraction) vapor composition (mole fraction) compressibility factor

\section{Greek Letters}

\author{
$\phi_{\mathrm{l}}, \phi_{\mathrm{v}}$ fugacity coefficients \\ $\omega \quad$ acentric factor \\ $\rho \quad$ density $\left(\mathrm{kg} / \mathrm{m}^{3}\right)$
}

\section{Subscripts and Superscripts}

$i \quad$ component number

$N$ total number of stages including the condenser and the reboiler

$k$ stage number

$\mathrm{v}$ vapor phase

1 liquid phase

\section{REFERENCES}

[1] G. Soave, Equilibrium constants from a modified Redlich-Kwong equation of state, Chem Eng Sci 27(1972), 1197-1203.

[2] J. W. Tester and M. Modell, Thermodynamics and its applications, 3rd edition, Prentice Hall, Upper Saddle River, NJ 1996.

[3] J. M. Prausnitz, R. N. Lichtenthaler, and E. G. deAzevedo, Molecular thermodynamics of fluid-phase equilibria, 3rd edition, Prentice-Hall, Englewood Cliffs, NJ, 1998.

[4] S. I. Sandler, Chemical and engineering thermodynamics, 3rd edition, Wiley, NY, 1999.

[5] E. L. Henley and J. D. Seader, Equilibrium-stage separation operations in chemical engineering, Wiley, NY, 1981.

[6] Z. Nasri and H. Binous, Applications of the Soave-RedlichKwong equation of state using Mathematica ${ }^{\mathbb{R}}$, J Chem Eng Jpn 40(2007), 534-538.

[7] Y. S. Choe and W. L. Luyben, Rigorous dynamic models of distillation columns, Ind Eng Chem Res 26(1987), 2158-2161.

[8] C. Fuentes and W. L. Luyben, Comparison of energy models for distillation columns, Ind Eng Chem Res 21(1982), 323-325.

[9] W. L. Luyben, Process modeling, simulation and control for chemical engineers, Chemical Engineering Series, 2nd edition, McGraw-Hill International Editions, NY, 1996.

[10] R. K. Wood and M. W. Berry, Terminal composition of binary distillation column, Chem Eng Sci 28(1973), 1707-1717.

[11] W. L. Luyben, Evaluation of criteria for selecting temperature control trays in distillation columns, J Process Control 16(2006), $115-134$.

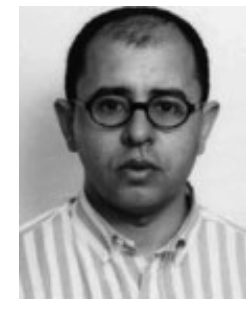

Housam Binous is a full-time faculty member at the National Institute of Applied Sciences and Technology in Tunis. He earned a Diplôme d'ingénieur in Biotechnology from the Ecole des Mines de Paris and $\mathrm{ahD}$ in Chemical Engineering from the University of California at Davis. His research interests include the applications of computers in chemical engineering. 